\title{
PROBLEMAS ONTOLÓGICOS DA FILOSOFIA DA TECNOLOGIA: NATURAL E ARTIFICIAL NA ÉTICA AMBIENTAL DE HOLMES ROLSTON III
}

\begin{abstract}
Professora de Filosofia no Instituto Federal Catarinense - Campus Camboriú. Doutoranda em Educação Científica e Tecnológica na Universidade Federal de Santa Catarina. Mestre em Filosofia pela Universidade Federal de Santa Catarina e Bacharela e Licenciada em Filosofia pela mesma Universidade. E-mail: leticialenzi@yahoo.com.br
\end{abstract}

\section{RESUMO}

A necessidade de se pensar a tecnologia é cada vez maior não apenas pela evidente relação das novas tecnologias com sérias questões de ordem ética que reclamam deliberação, mas principalmente porque a tecnologia influencia quase todos os âmbitos da nossa existência seja para permitir, melhorar ou facilitar a vida, seja para a produção sistemática de supérfluos que a ameaçam. Neste artigo evidenciam-se questões ontológicas relativas ao conceito de natural e a artificial no pensamento do filósofo ambientalista Holmes Rolston III, nome influente na construção de uma nova ética que promova o respeito pelo valor intrínseco da vida, considerando outras formas de vida como igualmente merecedoras de consideração moral. As concepções ontológicas elucidadas por este autor nos permitem esclarecer algumas de suas propostas políticas que preconizam um efetivo gerenciamento da Terra, tendo em vista maneiras de conservar e criar espaços aonde o ser humano possa respeitar os ciclos naturais, ao mesmo tempo em que permite a criação de domínios de síntese, de interação equilibrada entre a esfera da cultura e a da natureza.

PALAVRAS-CHAVE: Filosofia da Tecnologia. Ontologia. Ética Ambiental. Holmes Rolston III.

\section{ONTHOLOGICAL PROBLEMS OF TECHNOLOGY PHILOSOPHY: NATURAL AND ARTIFICIAL IN THE ENVIRONMENTAL ETHICS OF HOLMES ROLSTON III}

\begin{abstract}
The need to think about technology is increasing not only because of the evident relationship of new technologies with serious ethical issues that demand deliberation, but mainly because technology influences almost all areas of our existence either to
\end{abstract}


enable, improve or facilitate our life, or for the systematic production of superfluous things that threaten it. In this article, I bring some ontological questions related to the natural and artificial in the thinking of the environmentalist philosopher Holmes Rolston III, an influential name in the construction of a new ethic that promotes respect for the intrinsic value of life, considering other forms of life as equally worthy of moral consideration. In this article I bring light to the ontological conceptions elucidated by this author, and then present some of his political proposals that advocate an effective management of the Earth, considering ways to conserve and create spaces where human beings can respect natural cycles, at the same time in which it allows the creation of domains of synthesis, of balanced interaction between the sphere of culture and that of nature.

KEYWORDS: Philosophy of Technology. Ontology. Environmental Ethics. Holmes Rolston III.

\section{PROBLEMAS ONTOLÓGICOS DA FILOSOFIA DA TECNOLOGIA}

Historicamente, o estudo filosófico da técnica, enquanto capacidade humana de fabricar e usar artefatos, já aparece nos diálogos socráticos e mais precisamente nos escritos de Aristóteles ${ }^{1}$. No entanto, é apenas a partir da segunda metade do século XX, que o interesse em questões teóricas acerca da tecnologia ganha merecido destaque através de publicações e realização de inúmeros simpósios e congressos sobre o tema. Carl Mitcham, em Thinking through technology: the path between engineering and philosophy (1994), lembra que foi a partir dos esforços de Paul Durbin, professor da Universidade de Delaware nos Estados Unidos, que na década de setenta criou uma comunidade de estudiosos dedicados a investigar filosoficamente a tecnologia.

Durbin sustenta que aqueles que vêem como legítimo este movimento reconhecem duas coisas (1) há problemas urgentes relacionados à tecnologia e nossa cultura que requer clarificação filosófica e (2) muito do que já foi escrito sobre este problema é inadequado, sendo assim importante o engajamento e envolvimento de filósofos nesta questão. (MITCHAM, 1994, p. 10)

De fato, a necessidade de se pensar a tecnologia é cada vez maior, não apenas pela evidente relação das novas tecnologias com sérias questões de ordem ética que reclamam deliberação, mas principalmente porque a tecnologia está presente em quase todos os âmbitos

\footnotetext{
${ }^{1}$ Em Platão, no diálogo Górgias, há uma relação próxima da techne com episteme, ou logos. Techne se refere a todas as atividades que podem ser conhecidas suas razões ou comunicadas. Nesta mesma direção Aristóteles, em Ética a Nicômaco, sustenta que a techne é uma habilidade de fazer, que depende de um conhecimento correto ou razão sobre aquilo que é feito.
} 
da nossa existência, seja para permitir, melhorar ou facilitar a vida, seja para a produção sistemática de supérfluos que ameaçam destruir o essencial a manutenção da própria vida. $\mathrm{O}$ que se pode afirmar, é que esta crescente preocupação se dá a partir do momento que a tecnologia passa a ser um problema, refletido no modo de vida do homem contemporâneo, em seus aspectos cognitivos, em suas relações sociais e com formas de vida não humanas, ecossistemas e meio ambiente.

Na segunda metade do último século, o físico e conhecido filósofo da ciência Mario Bunge, mostrou a existência de importantes questionamentos filosóficos subjacentes ao fenômeno da tecnologia, não só na esfera ética, como no campo da epistemologia, axiologia e ontologia. Seus escritos serviram para a comunidade filosófica reconhecer um campo da filosofia até então pouco explorado e, sobretudo, para legitimar a filosofia da tecnologia como uma nova área de investigação ao lado das outras disciplinas já bem estabelecidas na tradição do pensamento filosófico.

Neste contexto, a filosofia tem o papel de nos informar e instrumentalizar conceitualmente para a tomada de decisões baseadas em razões bem fundamentadas, congruentes com os valores que pretendemos preservar e com um tipo de mundo que aspiramos construir. $\mathrm{O}$ reconhecimento do fato de que é apenas através de um maior esclarecimento conceitual que é possível direcionar a discussão sobre os reais problemas que envolvem a relação homem-máquina traz luz à importância de ser discutir os problemas ontológicos da filosofia da tecnologia. Assim, uma das questões que se sobressai é a própria compreensão do que vem a ser a natureza, o ser humano e a tecnologia e a relação entre essas esferas. Dependendo de como se entende estes conceitos, e das posições teóricas defendidas, diferentes conseqüências podem ser consideradas e julgadas em diferentes contextos.

Delinear o que entendemos a respeito dessas relações não é uma tarefa simples, mas é necessária frente à complexidade dos problemas que enfrentamos. Neste sentido uma das tarefas que compete à filosofia deve ser criar uma plataforma a partir de onde nossos problemas possam ser visualizados em sua inteireza e soluções possam ser consideradas julgadas. Filosoficamente pensar estes conceitos é algo que exige transcender as fronteiras das disciplinas filosóficas e trazer a tona questões que perpassam a ética, a política, a ontologia e a epistemologia. Mais do que isso, é uma área que muitas vezes requer ou exige um diálogo com outras áreas do conhecimento como a engenharia, a antropologia e a sociologia. 
Historicamente, como bem aponta Carl Mitcham, a reflexão filosófica acerca da relação do homem com a tecnologia se polarizou entre aqueles que defendem o avanço tecnológico e aqueles que, ao contrário, apontam os perigos que este avanço desenfreado é capaz de suscitar. Esta tensão pró e contra a tecnologia é compreensível desde que reconhecemos a complexidade do fenômeno tecnológico e as diferentes interpretações sobre seu significado.

O conceito de técnica e tecnologia não é unívoco, isto é, não significa a mesma coisa em todos os contextos. Há uma primazia de sua referência a atividade de fazer artefatos materiais, especialmente desde que este fazer tem sido modificado e influenciado pela ciência moderna. No entanto, cada definição, levanta um aspecto essencial da tecnologia, guiado por um foco restritivo. Assim, o que é necessário não é uma definição, mas um trabalho caracteriológico. Iniciando tal caracterização, a tecnologia pode ser descrita como a fabricação e o uso de artefatos. Esta característica não reflete a etimologia da palavra tecnologia, mas serve para demarcar o que deveria ser o escopo de uma preocupação filosófica com a tecnologia, delineando o que é único a este estudo. (MITCHAM, 1994 p. 153).

Para escapar de um discurso metafísico, no sentido de investigar a essência ou as propriedades essenciais da natureza, do homem e da tecnologia, uma tarefa difícil, sem nos comprometermos, em última instância, com um dado conjunto de crenças dogmáticas, a discussão recai sob a forma de categorias ontológicas.

No meu modo de entender, as categorizações filosóficas e ontológicas devem ser compreendidas como explicitações da estruturalidade instauradora da significatividade e da inteligibilidade das nossas práticas, falas e pensamentos, e não como explicações da estrutura das coisas mesmas. (...) A sua justificação, por conseguinte, não deve ser em termos de sua verdade ou não, mas antes de sua vigência, como propiciadoras de uma dimensão de sentido, validade e compreensibilidade. Real e irreal, verdade e falsidade, certo e errado, justo e injusto, adequado e inadequado, são já noções derivadas e fundadas na vigência de uma forma de validade e de significatividade. (BRAIDA, 2011, p. 08)

Distinguir a esfera do humano, da técnica e da natureza deve servir como bases teóricas para julgarmos os problemas decorrentes desta relação muitas vezes conflitante, para que se possa, por exemplo, de forma mais consciente, deliberar a favor ou contra a utilização de tecnologias em diversos contextos sociais e ambientais, e compreender as bases de muitos argumentos políticos, como por exemplo, os que defendem o valor intrínseco da natureza em 
prol de um desenvolvimento sustentável, base das éticas biocêntricas contemporâneas. O que diferencia e une o homem a natureza, e a própria técnica? Qual o status de ser de um artefato, que o difere dos entes naturais e do homem? Bunge (1985) elenca outros problemas que podem ser considerados parte de uma ontologia da tecnologia, apenas para citar alguns: quais são as características dos sistemas autocontrolados artificiais com relação aos naturais? Será algum dia possível cairmos sob o domínio completo das máquinas? É possível uma máquina capaz de levantar e elucidar problemas originais, e de praticar tanto o bem quanto o mal?

Nesta breve exposição, procuro mostrar como algumas concepções ontológicas sobre a interface natureza, homem e cultura, estão na base de concepções éticas contemporâneas, como a do filósofo americano Holmes Rolston III. Esta discussão é bastante interessante do ponto de vista filosófico, uma vez que cresce a motivação das pessoas em discutir e debater mais sobre uma nova ética, que abranja também aspectos ambientais. Para isso é necessário rever os limites da moral tradicional e estabelecer outros fundamentos ontológicos e princípios que coloquem no escopo da discussão interesses de seres vivos não humanos.

Tradicionalmente a filosofia moral considera apenas seres dotados de razão, vontade e liberdade como critério para definir quem entra para o círculo da comunidade moral, quem merece respeito moral. Ao adotar esses critérios assume-se uma postura antropocêntricahierarquizante ao colocar o ser humano no topo da escala biológica, onde as demais espécies vivas existem apenas para servi-lo. Tanto a tradição moral kantiana, quanto o utilitarismo humeano levam em conta apenas a moralidade de agentes morais e, portanto, legitimam todo ato de violência praticado contra quaisquer sujeitos, quando esses não se encontram em condições de defender seus interesses, fazendo uso da razão, liberdade e da linguagem. Tais critérios são incapazes de oferecer subsídios para a construção de uma ética de respeito à vida. Holmes Rolston III é um nome influente para a construção de uma nova ética que promove o respeito pelo valor intrínseco da vida, considerando outras formas de vida como merecedoras de consideração moral. Neste artigo trago luz às concepções ontológicas elucidadas por este autor, para em seguida apresentar algumas de suas propostas políticas que preconizam um efetivo gerenciamento da Terra, tendo em vista maneiras de conservar e criar espaços aonde o ser humano possa respeitar os ciclos naturais, ao mesmo tempo em que permite a criação de domínios de síntese, de interação equilibrada entre a esfera da cultura e a da natureza. 


\section{NATURAL E ARTIFICIAL: CONCEPÇÕES ONTOLÓGICAS NA PROPOSTA DE ÉTICA AMBIENTAL DE HOLMES ROLSTON III}

Holmes Rolston III é frequentemente identificado como o pai da ética ambiental como disciplina acadêmica moderna. Em seu livro de 1988, Environmental Ethics: Values in and Duties to the natural world, Rolston defende uma concepção ética de valor centrado na dimensão ecológica, em contraposição a ética tradicional antropocêntrica. Para Rolston, existe um valor intrínseco objetivamente nas espécies ou comunidades bióticas, sendo que a presença destes valores impõe ao humano certas obrigações diretas a entidades não humanas, tais como espécies ou ecossistemas. A defesa do valor intrínseco da natureza entra em choque com o modo de ver a natureza de forma instrumental, isto é, apenas valorada pela sua utilidade para um sujeito humano, a natureza como recurso, produto, ou resto.

Em um breve artigo intitulado Technology versus Nature: what is natural? Rolston expõe sua concepção ontológica da natureza na tentativa de responder uma questão central: $e ́$ possivel a tecnologia acabar com a natureza? Como o natural deve permanecer em um mundo cada vez mais tecnológico?

Rolston inicia articulando o conceito de tecnologia, como um corpo de conhecimento disponível a uma cultura, pelo desenho e uso de artefatos. Uma primeira abordagem a concepção de natureza, equivalente a physis grega, é a consideração de que natureza é tudo. Esta metafísica naturalista considera que todos os fatos, atuais e possíveis participam do natural. Neste sentido, a tecnologia é natural, pois nada escaparia ao conjunto do que se pode considerar como natureza. Por exemplo, o voar de um pássaro seria tão natural quanto um ser humano voar em um Boeing 777. A forte objeção a esta concepção, de acordo com o autor, é de não ser possível distinguir o que é natureza espontânea, a que está ai independente de nós, e a cultura deliberada. Uma distinção como esta é fundamental caso se pretenda relacionar as tecnologias com o ambiente natural, isto é, uma posição naturalista nestes termos encerraria uma discussão fundamental para o nosso tempo.

Além desta objeção, vale ressaltar uma inferência lógica do autor, quando sustenta que "um predicado natural, que inclui todas as propriedades reais e possíveis, e não exclui nada, denotando tudo, é como denotar nada ao mesmo tempo, ao menos nada em particular" (ROLSTON, 2007, p. 01, tradução nossa ). Em contrapartida, Rolston defende uma diferença 
irredutível entre natureza e cultura quando elucida que, inevitavelmente, toda a civilização produz artefatos em contraste aos produtos da natureza espontânea.

Natureza é vista como oposta a arte, o natural ao artificial. Natureza significa, não tudo que acontece, mas apenas aquilo que acontece sem a agência, ou sem a agencia intencional e voluntária do homem (...) Natureza é um termo para tudo que é por si mesmo, sem a intervenção humana voluntária. (ROLSTON, 2007, p. 1, tradução nossa).

Desta forma, cultura é entendida como algo exclusivo do humano, ou seja, animais não possuiriam cultura, embora alguns antropólogos possam discutir algum tipo de cultura em espécies de chipanzés, não haveria nenhuma clara evidência de transferência de estados mentais ou ideias se movendo de uma mente para a outra entre chipanzés, como entre uma criança e um professor. Em outros termos, não há evidências de cultura cumulativa transmissível e, portanto, também não pode haver qualquer desenvolvimento de tecnologia entre outras espécies de animais. A tecnologia, como um produto cultural humano, é outra em relação à natureza que, como visto em Rolston, corresponde a uma natureza selvagem ou espontânea.

No entanto, o dualismo natureza versus cultura não pode ser absoluto. De acordo com o autor: "Natureza é o ambiente da cultura, usando uma metáfora, natureza é o útero da cultura, mas um útero do qual o ser humano nunca sai inteiramente" (ROLSTON, 2007, p. 2, tradução nossa). Ou seja, a cultura sempre será construída a partir da natureza, que por mais que seja sistematicamente transformada pela cultura, sempre permanecerá como natureza circundante. A cultura não é logicamente nem empiricamente possível sem a natureza, mesmo que se pretenda destruir e acabar com toda a natureza, ainda assim restaria a natureza astronômica.

$\mathrm{O}$ que Rolston pretende enfatizar é que se caminha para uma Terra cada vez mais "manejável” ou "gerenciável”. Segundo o autor, o ser humano está expandindo a cultura para todos os espaços da Terra invertendo o quadro inicial, aonde antes existia uma tecnosfera dentro de uma biosfera, hoje e cada vez mais existe uma biosfera dentro da tecnosfera. Por conseguinte, isso nos leva a viver no que o autor chama de era pós-natural ou pósevolucionária, no sentido de que é a cultura o principal determinante do futuro da Terra e não mais as ordens naturais evolutivas. 
Se este é o caso, resta responder a uma pergunta: a natureza poderia chegar a um fim? É possível destruir a natureza? Para Rolston, embora pensemos que o homem possa destruir a natureza, ele nunca poderá fazê-lo completamente uma vez que a natureza circundante, pensada de forma ampla, como o sistema de suporte da vida, da existência e da própria cultura nunca pode acabar. "Em um lugar que podemos pensar que a natureza ali está quase terminada, onde humanos interferiram fortemente no curso natural, se olharmos por mais tempo, veremos que a natureza sempre retorna". (ROLSTON, 2007, p. 8).

De acordo com as categorias de Rolston, a conservação da natureza selvagem deve ser uma questão de grau, ou seja, por mais que não exista mais espaços na Terra inteiramente selvagens ou que não sofram quaisquer tipos de efeitos ou influências da ação humana, podese dizer que há ainda muitos espaços pouco influenciados pela cultura que devem ser conservados como tal. Neste sentido, caberia aos seres humanos a tomada de uma decisão crucial: queremos ou não transformar a Terra inteira em espaços dominados pela cultura? Queremos fazer parte de algo maior do que nós? A tendência é a resposta de que não queremos uma natureza totalmente homogeneizada, controlada de forma absoluta pela tecnologia e pelas máquinas. Se este for o caso, sustenta Rolston, é melhor permitir a existência de espaços naturais, selvagens, aonde as forças da natureza determinem o curso dos acontecimentos e não a cultura “(...) deve-se recuar e deixar que as coisas sejam elas mesmas. Isto nós fazemos precisamente reconhecendo a alteridade do selvagem, demarcando lugares selvagens, lugares que não permaneceremos, e que não restringiremos" (ROLSTON, 2007, p. 6, tradução nossa)

A proposta de Rolston, no entanto, não pode ser considerada conservacionista, no sentido de ver a cultura como algo inevitável e maléfico para a natureza e, portanto que deveríamos restringir a cultura e ter cada vez mais natureza selvagem. Para o autor, deve haver os dois domínios, ou seja, de um lado as cidades, espaços urbanos, dominados pela cultura e pelos artefatos, espaço de regras, tecnologias e políticas que determinam o curso dos eventos, mas por outro lado, grandes espaços aonde os eventos são gerados pela natureza espontânea, eventos que são o que são por si mesmos, onde há a maximização da natureza e a minimização do impacto cultural humano. Ao lado de ambientes urbanos e naturais, é possível criar um domínio de síntese e interação entre estes dois domínios, como resultado de um gerenciamento equilibrado entre cultura e natureza. 
[...] a interação simbiótica entre homem e natureza pode gerar ecossistemas mais diversos e mais interessantes que aqueles que ocorrem no estado selvagem. Usando conhecimento científico, diferentes culturas, e sabedoria ecológica nós podemos gerenciar a Terra para criar ambientes que são ecologicamente estáveis, economicamente lucrativos, e favoráveis ao contínuo crescimento da civilização. (ROLSTON, 2007, p. 6, tradução nossa).

O resultado desta simbiose é uma cultura humanizada, ambientes "seminaturais" cujo objetivo é permitir o domínio humano em um relacionamento sustentável com a natureza, em diálogo, em equilíbrio, em síntese, em simbiose com ela. Para criar esses espaços sustentáveis, é mister a promoção de três domínios: o natural, o cultural e a sua síntese. Por conseguinte, a cultura não deve dominar todo o território, assim como seria impensável a natureza selvagem dominar todos os espaços. Segundo o autor, é preciso ter os dois domínios, para se criar espaços de simbiose.

Rolston defende que uma ética ambiental e uma política ambientalista não são apenas sobre a conservação de uma natureza intocada, mas a vida humana em seu ambiente de forma equilibrada. Humanos em sua cultura, residindo também na natureza. Para isso é preciso um desenvolvimento sustentável com espaços gerenciados, e uma correta interação entre o ambiente urbano e o ambiente rural. Neste sentido as políticas públicas democráticas são fundamentais para se criar e fiscalizar leis de proteção da natureza que restrinjam a ação do humano em espaços determinados, protegendo da influência humana, montanhas, rios, flora e fauna. Por outro lado, desenvolver maneiras de conservar e criar espaços aonde o ser humano e sua cultura utilizem os recursos da natureza de maneira bem planejada, em diálogo, em simbiose com suas forças e ciclos.

A ética ambiental de Rolston traz a noção de que se valorarmos a natureza apenas por sua utilidade ou benefício gerado aos humanos, a motivação moral e política para a preservação da natureza será insuficiente, e neste contexto, a defesa do valor intrínseco da natureza pode proporcionar um incentivo moral mais eficaz em relação à criação de politicas públicas ambientais de conservação. Em outros termos, para que haja efetivamente políticas de desenvolvimento sustentável não basta o uso racional dos recursos naturais e sua conservação para as futuras gerações, mas também uma preocupação pela biodiversidade da natureza silvestre, pelo valor intrínseco que possui. Isto é, áreas naturais determinadas, com 
rica biodiversidade não deveriam ser desenvolvidas, mas conservadas. A preservação das riquezas biológicas, dos biomas, pântanos, rios e oceanos com toda a vida que contém, requer uma ética baseada no respeito a todas as formas de vida e por isso a ética do desenvolvimento deve dar lugar a uma ética do respeito à vida, para além de sua utilidade.

Por fim, um dos alcances da análise teórica de Rolston aqui apresentada é a possibilidade de substituirmos o termo "domínio" da Terra pelo termo "gerenciamento", planteando uma importante modificação semântica que nos leva ao papel de administradores, sugerindo outras relações com o meio natural, com um maior cuidado e equilíbrio entre a natureza e a cultura. Não menos importante, outros aspectos que Rolston também levanta é a necessidade de uma democracia participativa compatível com o uso racional da diversidade biológica. O gerenciamento da Terra e dos recursos requer não só o processo de apoio mútuo entre o desenvolvimento humano e a sua emancipação socioeconómica, mas deve estar unido à conservação do ambiente natural e da biodiversidade, ancoradas em uma nova ética que sustenta a vida e a própria cultura.

\section{REFERÊNCIAS}

BRAIDA, C. Ensaios ontológicos. Florianópolis:

Rocca Brayde, 2011.

BRAIDA, C. Entidades, objetidades $e$ formalidades. Florianópolis: Rocca Brayde, 2011.

BUNGE, Mario. Seudociencia e ideologia. Madri: Alianza, 1985.

CUPANI, Alberto. A tecnologia como problema filosófico. Scientia Studia. São Paulo, v. 2, n. 4, p. 493-518, 2004.

MITCHAM, C. Thinking through technology: the path between engineering and philosophy. Chicago: The University of Chicago Press, 1994.
ROLSTON, Holmes. Environmental Ethics: Values in and Duties to the Natural World. In.: BORMANN, F.; Herbert, KELLERT, Stephen R. (eds). Ecology, Economics, Ethics: The Broken Circle. New Haven: Yale University Press, 1991, p. 73-96.

ROLSTON, Holmes. Technology versus Nature: what is natural? Disponível em: < http://www.abdn.ac.uk/philosophy/endsandmeans /vol2no2/rolston.shtml>. Acesso em: 12 mai. 2017. 
LENZI, Letícia Problemas ontológicos da filosofia da tecnologia: natural e artificial na ética ambiental de Holmes Rolston III. Complexitas - Rev. Fil. Tem., Belém, v. 2, n. 1, p. 20-30, jan./jun. 2017. Disponível em:

<http://www.periodicos.ufpa.br/index.php/complexitas/article/view/4384>. Acesso em: 09 mar. 2018. 